\title{
Psicologia Histórico-Cultural e orientação profissional: vivências de jovens mobilizadas pela arte ${ }^{1}$
}

\author{
Fernanda Pereira Medeiros ${ }^{2}$ \\ Vera Lúcia Trevisan de Souza \\ Pontifícia Universidade Católica de Campinas-SP, Brasil
}

\section{Resumo}

$\mathrm{O}$ artigo apresenta o recorte de uma dissertação de mestrado, e tem como objetivo investigar a vivência de jovens do período pré-vestibular. Fundamentado no método materialista dialético, as informações foram construídas em 15 encontros, mediados por expressões artísticas, com um grupo de Orientação Profissional formado por alunos do terceiro ano do Ensino Médio de uma escola particular. Foram utilizadas duas categorias de análise: O silêncio que aliena X O silêncio que proporciona a análise crítica; Ser reconhecido X Ter aceitação incondicional. Como resultados, constatou-se que os jovens parecem se afastar das possibilidades de protagonismo de suas histórias, e a Orientação Profissional se configurou como espaço de ressignificação da relação dos jovens com os múltiplos cenários que constituem suas escolhas.

Palavras-chave: adolescência, orientação vocacional, psicologia histórico-cultural, psicologia escolar

Abstract: Historical-Cultural Psychology and professional orientation: experiences of young people mobilized by art The article presents the results of a master's thesis, and aims to investigate the experience of senior high school students. Based on the dialectical materialist method, the information was constructed in 15 meetings, mediated by artistic expressions, with a Professional Orientation group formed by third year students of a private high school. Two categories of analysis were used: The silence that alienates $\mathrm{X}$ The silence that provides the critical analysis; Be recognized X Have unconditional acceptance. As a result, it was found that the young people seem to distance themselves from the possibilities of protagonism of their stories, and the Professional Orientation was configured as a space of resignification of the relation of the young people with the multiple scenarios that constitute their choices.

Keywords: adolescence, vocational orientation, historical-cultural psychology, school psychology

Resumen: Psicología Histórico-Cultural y orientación profesional: vivencias de jóvenes movilizadas por el arte El artículo presenta resultados de una tesis de maestría en la que se investigaron las vivencias de jóvenes preuniversitarios de una escuela privada. Fundamentándonos en el método materialista dialéctico, las informaciones fueron construidas en 15 encuentros mediados por expresiones artísticas de un grupo de orientación profesional formado por alumnos del tercer año de la Enseñanza Media. Se utilizaron dos categorías de análisis: El silencio que aliena X El silencio que proporciona el análisis crítico; Ser reconocido X Tener aceptación incondicional. Como resultados, se constató que los jóvenes parecen distanciarse de las posibilidades de protagonismo de sus historias, y la Orientación Profesional se configuró como un espacio de resignificación de la relación de los jóvenes con los múltiples escenarios que constituyen sus elecciones.

Palabras clave: adolescencia, orientación vocacional, psicología histórico-cultural, psicología escolar

\footnotetext{
${ }^{1}$ Agradecimentos à Comissão de Aperfeiçoamento de Pessoal do Nível Superior - CAPES - pelo apoio recebido para o desenvolvimento deste trabalho.

${ }^{2}$ Endereço para correspondência: Rua José de Oliveira Borges, 62, 13034-050, Campinas, SP. E-mail: fernandapereiramedeiros@gmail.com
} 
$\mathrm{O}$ artigo apresenta resultados de uma dissertação de mestrado em que se investigou a vivência de jovens de uma escola particular do período pré-vestibular. O objetivo norteador da pesquisa foi, a partir de um modelo de Orientação Profissional pautado nos pressupostos da psicologia histórico-cultural, compreender como os adolescentes do $3^{\circ}$ ano do Ensino Médio privado vivenciavam o período pré-vestibular e de que modo essa vivência impactava suas escolhas profissionais. Para este trabalho, foram considerados um conjunto de resultados a partir de duas categorias de análise: O silêncio que aliena X O silêncio que proporciona a análise crítica; Ser reconhecido X Ter aceitação incondicional. As duas categorias elencadas apresentam alguns dos cenários constituintes das escolhas profissionais dos jovens, que atuam na configuração dos modos de pensar o mundo e a si próprios em relação à escolha e ao futuro. Os jovens parecem se afastar das possibilidades de protagonismo de suas histórias e, assim o momento de Orientação Profissional passou a se configurou como espaço de ressignificação das relações dos jovens com os múltiplos cenários que constituem suas escolhas.

\section{Psicologia Histórico-Cultural e Orientação Profissional: breves considerações}

O surgimento dos vestibulares no Brasil, enquanto exames de admissão ao Ensino Superior, remonta a 1911. A valorização do Ensino Superior passou então a direcionar o Ensino Médio brasileiro, especialmente no âmbito privado, configurando suas bases em um ensino adaptado à preparação do aluno para o êxito e aprovação nos exames de acesso ao Ensino Superior, o vestibular (D`Avila $\&$ Soares, 2003).

Para Whitaker (2010), D`Avila e Soares (2003), a preocupação com a aprovação nos processos seletivos das universidades também impacta na redução de espaços direcionados à busca de reflexão sobre o processo de escolha, visto que é dada ênfase aos conteúdos que possivelmente serão cobrados ao jovem no contexto de avaliação. Alvim (2011) sustenta que o Ensino Médio se tornou palco de preparação ao vestibular e gerador de ansiedades, autopunições ou momento de lidar com as possibilidades de fracasso que os jovens podem apresentar nos vestibulares. Sendo o momento de escolha profissional um evento gerador de medo, pressão e dúvida, seja no âmbito privado ou público, é nas ações de exploração vocacional ou pelas falas dos professores no cotidiano escolar que os jovens passam a balizar suas escolhas de vida e carreira.

Se tomarmos como base o Ensino Médio brasileiro enquanto momento da formação que deveria preparar o jovem para a continuação dos estudos ou para o mundo do trabalho, há que se questionar o lugar de protagonismo desses jovens nesse ensino. Quais são os momentos, seja no âmbito privado ou público de educação, em que são indagados e provocados à reflexão sobre o próprio mundo do trabalho ou do Ensino Superior?

Para compreender essas questões tomamos como referencial a Psicologia Histórico-Cultural de Vigotski, que chama a atenção para a importância do meio social enquanto fonte de desenvolvimento do sujeito. Angel Pino (2000), em artigo publicado na revista Psicologia e Sociedade que publica o inédito Manuscrito de 1929 de Vigotski, se dedica a explicar a compreensão do autor do social e cultural no desenvolvimento da criança, conceitos abordados por Vigotski no Manuscrito, mas, como outros, não suficientemente explicitados. Nas palavras do autor:

O social ao qual Vigotski se refere especificamente é o social humano, cuja emergência, com maior razão que a das formas animais de sociabilidade, tem de ser explicada por princípios outros, e não os meramente naturais ou biológicos. As formas humanas de organização social, em que a sociabilidade natural se concretiza, são obra do homem e, como tal, obedecem a leis históricas que determinam as condições concretas de sua produção. É o caráter histórico dessa produção que define o social humano. (Pino, 2000, p.60)

É esta concepção de social na teoria de Vigotski (1935/2010) que sustenta seus conceitos de Situação Social de Desenvolvimento e de Vivência, os quais tomamos como centrais na análise da pesquisa. Por hora, importa afirmar que para a Psicologia Histórico-Cultural de Vigotski, o social assume tamanha relevância que não é possível ao homem se humanizar fora da cultura, das relações sociais, onde reside a fonte das produções humanas que, uma vez acessadas, possibilitam o desenvolvimento das funções psicológicas superiores. Assim sendo, ao nascer o indivíduo dispõe do potencial para se tornar humano, dado pelas funções psicológicas elementares que, na relação com as produções culturais, mediada pela linguagem e seus processos de significação, se apropria dos meios humanos para agir no mundo.

Logo, não podemos esperar que os jovens sejam autônomos e críticos no Ensino Superior caso não tenham tido acesso a formas culturais promotoras de relações autônomas e pensamento crítico. Ao assumir a dialética, Vigotski nos leva a compreender a constituição mútua entre sujeito e sociedade, conferindo ao social uma dimensão ontogenética no desenvolvimento do homem e do sujeito. 
A configuração do social em individual é explicada pelo conceito de perezhivanie ${ }^{3}$. (Vigotski, 1935/2010).

Perezhivanie, ou vivência, é caracterizada enquanto unidade indivisível que contém as características do meio e o modo como essas características constituem o desenvolvimento da consciência do indivíduo. O que temos acesso não são as vivências em si, e sim, o contexto em que são configuradas as situações sociais de desenvolvimento capazes de produzir vivências nos sujeitos (Vigotski, 1935/2010). O modo como o sujeito vivencia determinada situação é que irá configurar seu desenvolvimento, ou seja, não há como separar sujeito e meio, pois toda vivência está apoiada em uma articulação real, e dinâmica, entre o meio e o sujeito. $\mathrm{O}$ que significa dizer que para Vigotski (1931/2006), a vivência não pode ser entendida fora da situação social de desenvolvimento, das condições produzidas pelo meio em que o sujeito está inserido. Entretanto, esses aspectos que se constituem como situações sociais de desenvolvimento não estão dados a priori, são construídos nas interações que se empreendem no contexto (Veresov, 2012).

A lei postulada por Vigotski nos faz compreender que, ao mesmo tempo em que o sujeito tem papel ativo em sua constituição, essa depende de condições materiais que propiciem sua humanização (Petroni 2013), condições essas, denominadas por Vigotski (1935/2010) de situação social de desenvolvimento. Essa acepção permite pensar a Orientação Profissional ${ }^{4}$ como uma situação social de desenvolvimento que promove a vivência da escolha profissional como movimento de configuração de novos significados e sentidos, de ampliação da consciência.

É possível, portanto, assumir como objetivo da Orientação Profissional pautada nos pressupostos da Psicologia Histórico-Cultural enquanto uma das múltiplas práticas do psicólogo na escola, intervir no meio de forma que favoreça a configuração de situações sociais de desenvolvimento capazes de configurar vivências que possam ressignificar a escolha profissional, a relação com o trabalho e a própria relação do jovem com o ambiente escolar. É por meio das situações sociais de desenvolvimento que os sujeitos são capazes de se apropriar das significações da cultura que resultam no desenvolvimento das funções psicológicas superiores, como o pensamento por conceito, que, por sua vez, pode resultar em processos como a autorregulação da conduta e a capacidade de fazer escolhas (Vigotski, 1932/2001; 1931/1995).

Vigotski (1932/2001) deixa clara a diferenciação entre pensamento e fala por compreender que a integração destas duas funções dá origem ao pensamento por conceito que está na base de modos mais elevados de pensamento - constituição da consciência, imaginação e do pensamento crítico. Isto ocorre pelo fato de que quando o pensamento não encontra sua expressão na palavra, ou em outro signo, como gesto, desenho, imagem, deixa de existir, não se constituindo como fonte de transformação de si e do meio. Essa postulação de Vigotski nos faz questionar quais são os espaços de fala propiciadores de pensamento que os jovens estudantes possuem no contexto escolar atual.

É de se esperar que as relações que se estabelecem no ambiente escolar se constituam como situação social de desenvolvimento promotoras de vivências que favoreçam a reconfiguração de sentidos pelos jovens no que concerne ao ingresso no Ensino Superior. Mas, quais são as condições que a escola dispõe para o jovem pré-vestibular, se tomarmos como base o modo tradicional como está estruturado o período escolar que antecede os exames de acesso ao Ensino Superior?

Algumas instituições de ensino têm buscado contemplar um momento dedicado à escolha profissional ao oferecer espaço ao que se nomeia de Orientação Profissional. Alvim (2011) evidencia a necessidade de se investigar qual o papel da escola na construção dos conceitos de trabalho e escolhas nos jovens pertencentes a ela, visto que a escola acaba se constituindo enquanto referência na orientação do jovem. Ou seja, é por meio da escola que o jovem se apropria dos significados da cultura a que pertence. Além disso, se partimos de uma perspectiva histórico-cultural do desenvolvimento, entendemos que são os significados e os sentidos que realizam a mediação entre o pensamento e a linguagem, configurando a constituição da subjetividade dos sujeitos (Vigotski, 1932/2001).

\footnotetext{
${ }^{3}$ Perezhivanie é um termo russo de difícil tradução. Seguindo o trabalho realizado por Prestes (2010) buscamos pela tradução do espanhol, vivência, por compreendermos, assim como a autora, que é o termo que mais preserva a concepção de meio e ao mesmo tempo de singularidade do sujeito diante da análise de um determinado fenômeno.

${ }^{4}$ Ao longo da constituição histórica, foram atribuídos diferentes sentidos e significados à denominação Orientação Profissional. A partir do período denominado Revolução Industrial e ancorado pelo modelo de produção capitalista, deu-se origem à divisão técnica de trabalho e, consequente valorização da seleção e da escolha da profissão, pois no novo modelo o homem poderia escolher entre as diversas opções, qual seria sua ocupação (Bock, 2001; Oliveira, 2009). Na presente pesquisa optou-se pelo termo "Orientação Profissional" entendendo-a como uma conduta, portanto, mais relacionada a fenômenos concretos e, por conseguinte, mais próxima do que se propõe o materialismo histórico dialético.
} 
Ressalta-se, assim, a importância de um trabalho em Orientação Profissional que possibilite a ressignificação do momento de escolha profissional. Visto que, como bem demonstra Oliveira (2009), tratam-se de jovens inseridos em uma cultura que significa o momento de escolha profissional por meio de uma ótica neoliberal que não admite fracassos e prega, constantemente, a necessidade de retorno financeiro imediato acima de qualquer satisfação pessoal em relação à profissão elegida.

Para Vigotski (1931/1995), escolha significa um processo complexo e fundamental para o desenvolvimento das funções psicológicas superiores. Aguiar (2006) infere a partir desse pressuposto que para compreendermos o processo de escolha, é necessário atentar-se para as mediações sociais e históricas que constituem esse processo. Assim, é preciso apreender como os sujeitos configuram determinações postas por essas mediações e compreender o processo de escolha a partir de uma discussão que apreenda tanto o histórico, o social e o modelo ideológico em que esse processo se desenvolve.

Em sua maioria, as escolas que contratam esse profissional estão mais preocupadas em oferecer o serviço enquanto bem de troca e marketing. Poucos são os profissionais de orientação que pautam suas práticas no favorecimento da ampliação da consciência dos jovens que realizam a escolha. Por hora, podemos perceber que em uma classe social que parece favorecer as possibilidades de escolha visto as condições materiais que é capaz de oferecer, a escolha tem resultado na opção por profissões que possam manter o padrão social e econômico dos jovens, o que limita seu poder de escolha (Alvim, 2011; Alvim \& Menin, 2012).

Conde (2012) alerta sobre os caminhos tomados pela Orientação Profissional até então que acabam, por meio de análises de respostas, testes e questionários, dando ao orientador o papel central no processo de escolha do jovem. Ou seja, nesses casos é o orientador que detém as informações sobre o adolescente a partir dos resultados dos instrumentos utilizados, e acaba por desresponsabilizar o próprio jovem das consequências de suas escolhas, ao atribuir aos testes a decisão por uma carreira em detrimento de outras.

Será esse o trabalho do orientador profissional dentro da instituição escolar? Ou esse deveria ser o profissional que favorece espaços de protagonismo do aluno nesse ambiente que por vezes tanto o destitui desse direito?

Essas práticas concorrem com autores que buscam priorizar uma Orientação Profissional pautada nos aportes da Psicologia Histórico-Cultural, com uma visão de homem que é produto e produtor de seu meio social (Bock, 2002; Aguiar \& Ozella, 2006). Portanto, práticas com o objetivo de ampliar a compreensão acerca da realidade do jovem às vésperas de realizar suas escolhas profissionais.

É com base na perspectiva desses profissionais que assumem uma visão crítica de desenvolvimento humano que este trabalho propôs uma atuação do psicólogo escolar, por via da Orientação Profissional, por meio do uso da arte, com vistas a promover vivências que pudessem ser capazes de ressignificar o momento da escolha profissional desses jovens.

$\mathrm{Na}$ perspectiva Histórico-Cultural, a Orientação Profissional deve oportunizar espaços de autoconhecimento dos sujeitos enquanto indivíduos multideterminados, a fim de que ressignifiquem as próprias percepções de si, seus posicionamentos e relações que configuram o mundo que os rodeia e assim possam se encontrar com os respectivos projetos de vida (Oliveira, 2009; Bock, \& Aguiar, 1995).

O objetivo principal é, portanto, proporcionar uma reflexão sobre a escolha profissional, ao se considerar os determinantes histórico-sociais, desenvolver uma visão crítica em relação ao mundo do trabalho, da profissão e da própria escolha. Dessa forma, a Orientação Profissional favorece a conscientização do sujeito dos principais determinantes da escolha, favorecendo que assuma o protagonismo da escolha (Oliveira, 2009). A proposta é de ampliação do olhar no que se refere à escolha profissional, principalmente no que diz respeito ao modo como as escolhas são realizadas, levando-se em conta as vivências de cada um, o que os leva a escolher determinada profissão e não outra, resgatando a dimensão histórica desses sujeitos, a dimensão histórica da construção de sua identidade. Ou seja, contribuir para que os jovens se apropriem do processo que os configura e, principalmente, de suas determinações, para que, dessa forma, possam se tornar mais capazes de atuar, enquanto protagonistas de suas respectivas histórias. (Aguiar, Bock, \& Ozella, 2007).

Ao compreendermos o trabalho do orientador profissional do modo como descrito acima, nos aproximamos dos objetivos de uma atuação do psicólogo no cotidiano da escola proposta em muitos trabalhos desenvolvidos pelo grupo de pesquisa Processos de Constituição do Sujeito em Práticas Educativas - PROSPED, que orienta suas múltiplas práticas de pesquisa no espaço escolar com trabalhos sempre mediados pela arte (Petroni, 2013; Petroni \& Souza, 2014; Souza, Petroni, \& Dugnani, 2011). Ao compreender que o espaço de atuação do psicólogo escolar permanece em construção na escola, o PROSPED resgata na obra de Vigotski a sua aproximação com a Psicologia da Arte e propõe o uso de diferentes produções artísticas como forma de promover vivências, no caso, relacionadas à escolha da profissão. 
Clot (2014), ao discorrer sobre a relação da arte e a consciência nas obras de Vigotski, afirma que a arte serve como um caminho para colocar a emoção e o pensamento em movimento, oferece ideias novas como fonte de mudança para os afetos. Esse movimento só é possível, porque a arte tem caráter dialético, contém em sua estética a própria contradição, o que dá forma ao inacabado e permite a transformação das relações do sujeito com o meio. Dessa transformação das relações do sujeito deriva uma nova qualidade das funções psicológicas superiores, visto que há nova compreensão de si e de realidade, há ampliação de consciência.

Especificamente, na Orientação Profissional com o uso da arte, podemos dispor da contradição que confronta os sentimentos opostos entre alcançar a independência profissional e ao mesmo tempo arcar com a responsabilidade dessa mesma escolha profissional, ou mesmo acessar, pela via da imaginação, um futuro possível sem se desprender do tempo presente na realidade. É nesse sentido que acreditamos, enquanto grupo de pesquisa, que a arte proporciona ao sujeito uma relação libertadora com o mundo por vias da imaginação. É a imaginação que permite ao jovem se antever no futuro, imaginar-se em uma ou em outra profissão e antecipar as consequências de sua escolha por dada profissão ou não. Ao inserir uma obra de arte - um filme ou música - em sua prática profissional, a intencionalidade está em transformar as relações desse sujeito com a realidade a fim de garantir a promoção de seu desenvolvimento, sua tomada de consciência sobre as condições de sua existência e das possibilidades de atuação em sua própria realidade.

Desse modo, o trabalho do orientador profissional e psicólogo inserido no contexto escolar está fundamentado no papel de mediador, como sujeito que organiza o meio de forma que este se constitua como situação social de desenvolvimento capaz de proporcionar vivências que, por sua vez, promovem a ressignificação do modo de viver, sentir e perceber a realidade do jovem diante da escolha profissional.

\section{Método}

Esta pesquisa se filia à abordagem qualitativa, do tipo participativo e com características de pesquisa intervenção. Assume os pressupostos teóricos metodológicos da Psicologia Histórico-Cultural, sobretudo os de Vigotski (1931/1995), que defende o estudo do fenômeno da forma como ele aparece na realidade, apreendendo-o em movimento, considerando as contradições e tensões que o caracterizam.
A pesquisa foi aprovada pelo Comitê de ética em pesquisa da Pontifícia Universidade Católica de Campinas sob protocolo 1.367 .904 e foi realizada em uma instituição privada de Ensino Médio, localizada na região central de uma grande cidade do interior do estado de São Paulo. A instituição foi escolhida pelo critério de viabilidade, visto que a pesquisadora estava inserida neste espaço como Orientadora Educacional.

Os participantes foram 20 alunos do $3^{\circ}$ ano do Ensino Médio, entre 16 e 18 anos, sendo 4 do sexo masculino e 16 do sexo feminino, que aceitaram frequentar o grupo de Orientação Profissional em período de contra turno às aulas. Entre as profissões que os alunos participantes se interessavam estavam: Direito, Medicina, Psicologia, Pedagogia, Física, Carreira Militar, Letras e Economia.

Foram 15 encontros, com periodicidade semanal e duração de duas horas cada. Em todos os encontros eram apresentadas expressões artísticas para apreciação dos participantes e, posteriormente, investia-se em práticas dialogadas sobre as impressões do observado, sentido ou vivido. Dentre as expressões utilizadas no trabalho estão a apresentação de fotografias, filmes, documentários, apreciação de obras artísticas, confecção de pinturas, esculturas e recortes.

Apesar de se ter um planejamento prévio dos encontros, foram necessários ajustes de acordo com o modo com que os adolescentes se relacionavam com as propostas de reflexão no decorrer de cada encontro. Os encontros foram gravados em áudio e transcritos. Além disso, realizou-se anotações das observações realizadas durante a pesquisa-intervenção em diários de campo, sendo tal ação efetuada após os encontros e no cotidiano escolar em que estava inserida a pesquisadora. Foi esse o material usado para a construção das análises e discussões apresentadas posteriormente. Por se tratar de um recorte da pesquisa, serão discutidos os resultados de apenas duas categorias de análise presentes na dissertação de mestrado da qual derivam os dados discutidos no presente artigo. As categorias em questão são: $\mathrm{O}$ silêncio que aliena $\mathrm{X} O \mathrm{O}$ silêncio que proporciona a análise crítica; Ser reconhecido X Ter aceitação incondicional.

\section{Resultados e discussão}

Ao tomarmos como prática orientadora a máxima de Vigotski (1931/2006) de que nos tornamos nós mesmos através dos outros, pudemos ir desvelando os vários cenários que mobilizavam as escolhas e o consequente sofrimento dos jovens. Na escola, nas famílias, entre os amigos e grupos a que pertencem, os adolescentes configuram seus modos de ver e pensar o mundo e, consequentemente, 
o mundo do trabalho que pretendem ingressar. É por meio da configuração desses diversos cenários que o adolescente constitui suas escolhas, como elucida Vigotski $(1935 / 2010)$ ao afirmar que o meio é fonte de desenvolvimento humano.

Entretanto, a análise desses cenários revelou que todos - a família, os colegas, a escola, os professores, o modelo de produção característico do sistema capitalista e as configurações do mercado de trabalho neoliberal, de alguma forma, acabam por produzir e sustentar o sofrimento que caracteriza esse momento da vida dos jovens.

Para fins deste artigo, buscaremos enfatizar um recorte de duas categorias de análise da pesquisa em questão - $\mathrm{O}$ silêncio que aliena $\mathrm{X} \mathrm{O}$ silêncio que proporciona a análise crítica; Ser reconhecido X Ter aceitação incondicional - que elucida o modo como os jovens vivenciavam a relação com os múltiplos cenários constituintes das vivências do período pré-vestibular.

\section{$O$ silêncio que aliena $X O$ silêncio que proporciona a análise crítica}

Em diferentes momentos de socialização com os professores da escola, era comum se deparar com a queixa de apatia dos alunos do $3^{\circ}$ ano em relação ao conteúdo e desenvolvimento das aulas. O silêncio em sala, na maioria das vezes, era visto como um silêncio de apatia dos alunos, desinteresse pela matéria.

No grupo de Orientação esse sentimento também esteve presente em alguns encontros. Os jovens, por vezes, pareciam não fazer associações ou alcançar reflexões críticas a respeito das atividades. Entretanto, no decorrer dos encontros de Orientação, alguns alunos trouxeram falas importantes para desmistificar o fenômeno considerado como apatia pelos educadores. Um exemplo dessas falas segue no depoimento do aluno $\mathrm{T}^{5}$. a partir do filme Entre os Muros da escola:

T: Por exemplo, no terceiro ano, na nossa sala é todo mundo quieto demais, quase ninguém pergunta. Porque, se a gente pergunta no terceiro ano, tem coisas que a gente fala que o professor diz: 'você está no terceiro ano e não sabe isso?' E, às vezes tem tanta coisa mais difícil que a gente sabe, mas isso não sabia, entendeu? (Trecho da transcrição do $13^{\circ}$ encontro, diálogos a partir do filme Entre os muros da escola.)
Assim, podemos reavaliar os momentos de silêncio constantes no grupo de Orientação Profissional, como descrito, a seguir, em diário de campo da pesquisadora:

Ao final do encontro, entreguei para cada um deles uma imagem da escultura Freedom, de Zenos Frudakis, na Filadélfia, Pensilvânia, e pedi que me dissessem o que a imagem representava para eles. Alguns expressaram palavras como movimento, continuidade; o aluno T. completou dizendo liberdade. Eu retomei dizendo que gostaria que eles entendessem que aquela seria a representação do que eu gostaria que o espaço do grupo de Orientação Profissional fosse para cada um deles, um processo de escolha pautado na liberdade de escolha que tanto falamos durante as discussões no documentário. Muitos ficaram em silêncio. $O$ aluno T. sorriu e perguntou onde ficava aquela escultura e se ela era real. Conversamos sobre o lugar onde ela estava e passei o nome do autor e encerramos o encontro. (Trecho do diário de campo do $1^{\circ}$ encontro do grupo, reflexões a partir da escultura Freedom de Zenos Frudakis.)

O silêncio dos alunos em relação à imagem da escultura Freedom não parece ser semelhante àquele que se manifesta na sala de aula diante da incompreensão de alguma atividade. Muito tempo depois de terminado o grupo, uma das participantes, que já não era mais aluna do colégio em que os encontros aconteciam, fez menção à pesquisadora em uma rede social quando se deparou com a mesma imagem Freedom, e escreveu o quanto sentia saudades daqueles encontros em grupo mesmo tendo concluído o Ensino Médio.

Esse silêncio se fez presente ainda em outras situações que não eram acompanhados de sinalização de desinteresse ou falta de motivação em relação às atividades propostas. Um exemplo marcante foi a reação dos jovens às fotos do fotógrafo social Sebastião Salgado em Serra Pelada:

Quando contei para os alunos que dentre aqueles homens retratados não havia nenhum que estivesse ali contra a própria vontade, muitos ficaram em silêncio olhando as fotos que ainda estavam sendo reproduzidas na frente da sala. Antes que soubessem do que se tratava a realidade das fotos e questionados sobre

\footnotetext{
${ }^{5}$ Para garantir o anonimato dos participantes da pesquisa todos os nomes foram mantidos com as iniciais de seus respectivos nomes, atendendo à solicitação dos próprios jovens que sabendo fazer parte de uma pesquisa científica solicitaram à pesquisadora que não usasse nomes fictícios, mas sim, as iniciais de seus próprios nomes.
} 
quais profissionais acreditavam que melhorariam as condições de vida na realidade retratada nas fotos, todos haviam colocado o advogado, juiz para que garantissem as leis trabalhistas daqueles homens que os alunos, quando mencionavam diziam se parecer com escravos. Retomei esse posicionamento dizendo a eles que a única escravidão que mantinha aqueles homens naquele espaço era o desejo de se tornar um homem rico. Foi impressionante as feições de cada um e muitos demonstraram perceber a contradição que estava presente naquele momento, pois enquanto todos estavam tentando encontrar profissionais que dariam condições para tirar aqueles sujeitos daquela situação, os próprios sujeitos não queriam sair daquele espaço.

Quando encerramos o encontro, os alunos me ajudaram a arrumar a sala, mas permaneciam nela, mesmo depois que nos despedimos. Permaneciam conversando sobre outros assuntos que não o assunto do encontro, mas permaneciam apesar de já terem se passado mais de 2 horas que estávamos lá reunidos. (Trecho do diário de campo do $7^{\circ}$ encontro, discussões a partir das fotos de Sebastião Salgado sobre a Serra Pelada.)

Quando, por meio da arte, a contradição se faz emergir, uma reação dos alunos é o próprio silêncio. Poderíamos nomeá-lo como vivência estética, pois o silêncio para esses jovens parece se configurar como um momento que possibilita a migração dos afetos que só pode ocorrer se houver espaço para ressignificar essa vivência (Clot, 2014).

O silêncio, portanto, é marcado por ruídos:

P: Então, no filme vamos encontrar alguns pontos muito discrepantes e outros muito semelhantes. Vocês viram que no início tem muito barulho na sala de aula, de conversa, de briga dos alunos.

T: Tem muito barulho interno também. (Trecho da transcrição do $12^{\circ}$ encontros, diálogo a respeito do filme Entre os muros da escola.)

Essa fala de T. traz o modo como o sujeito vivencia o espaço da sala de aula, ou seja, é no silêncio que é denominado como apatia que se configuram os maiores ruídos de sofrimento desses jovens. Mas, quais são os espaços que favorecem o diálogo sobre esses ruídos?

O silencio parece se configurar como apatia, porque o contexto é tão opressor que passa a impedir as possibilidades de escolha profissional sustentadas na reflexão crítica sobre si e sobre o próprio contexto. Quais são os espaços para a quebra desses silêncios? Pode ser sim que a adolescência seja marcada por uma introspecção maior como defendem alguns teóricos do desenvolvimento, mas quando são garantidos os espaços de diálogo e protagonismo, será que esses jovens não desejam se expressar?

Se dado um ponto do desenvolvimento do sujeito, pensamento e linguagem formam uma unidade dialética (Vigotski, 1931/2006) e inclusive norteiam em tempo integral a fala interna, há que se compreender que o pensamento e linguagem estão sempre presentes, mesmo que não sejam vocalizados.

Assim, podemos inferir que não se trata de falta de interesse do jovem, mas que a atividade proposta, seja na escola, na família ou em qualquer outro nível social, já não é mais o motivo vencedor da ação de prestar a atenção desse jovem (Clot, 2014). Resta-nos compreender quais são os motivadores que norteiam a ação desses jovens e quais afetos estão na base desses pensamentos.

Entretanto, para que possamos acessar as emoções que estão na base e colocá-las a favor do domínio da própria conduta que propicia o comportamento de escolhas (Clot, 2014; Vigotski, 1931/2006) precisamos de jovens que não estejam em sedentarização afetiva, precisamos que a emoção se manifeste para que possam elaborar, pensar e nomear essas emoções. Daí a necessidade de um espaço de escuta e protagonismo desse jovem nos múltiplos cenários que constituem suas escolhas, principalmente no âmbito escolar.

\section{Ser reconhecido $\mathrm{X}$ Ter aceitação incondicional}

Em diferentes momentos no decorrer dos encontros, os alunos expressaram a necessidade de serem reconhecidos. Seja pela profissão ou em relação aos familiares e mesmo no contexto escolar. Observe o trecho destacado da transcrição do áudio do $6^{\circ}$ encontro:

[Imagem Sky and Water - M.C. Escher]

R: O que? A gente? Ai, vamos lá. Esse aqui eu não sei, o cara deve ter fumado um! São pássaros e peixes. Eu percebi que os pássaros que estão abaixo não têm detalhe nenhum e o pássaro mais em cima é cheio de detalhe. Os peixes que estão no meio também não tem detalhe nenhum, agora o peixe que está lá no fundo é cheio de detalhes. Dai a gente pensou que quanto mais alto você está, mais qualidades você tem, quanto mais baixo você está, mais detalhes as pessoas veem em você. (Trecho da transcrição do $6^{\circ}$ encontro, diálogos a partir da atividade de leitura das imagens de Escher, especificamente neste trecho, leitura da imagem Sky and Water.) 
A partir da atividade de leitura e apreciação das imagens de M. C. Escher, observamos a valorização e a necessidade de se destacar, ou seja, de acordo com os alunos ser o melhor é identificado como o sujeito de maior poder, aquele que mais possui características notáveis diante dos demais.

Ao falarem sobre o que identificam nas imagens de Escher, os jovens são provocados a pensar sobre suas escolhas por meio de uma nova lógica que é a lógica da arte. Corroboramos as ideias da tese de doutoramento de Vigotski (1925/2001) de que a arte é capaz de despertar nos sujeitos afetos e sentimentos para além do âmbito individual, pois o artista que a produz busca favorecer o reconhecimento do humano no símbolo que é a obra. É no movimento de leitura das imagens de Escher, em um grupo de Orientação Profissional que se propõe o diálogo sobre as escolhas profissionais dos jovens, que o adolescente tem a possibilidade de expressar o que vem mediando suas escolhas e que não está aparente no cotidiano. Como salienta Clot (2014) é por meio da arte que ideias novas se tornam fonte de mudança dos afetos, que transformam as relações do sujeito com o meio. No caso da imagem de Escher parece claro que ser reconhecido, estar acima dos demais, é mais valorizado do que estar por baixo. Entretanto, quando falam de quem está mais baixo, destacam os olhares dos outros sobre si mesmos, caracterizando a intensa pressão social a que são submetidos no momento de escolha profissional.

O reconhecimento e valorização também estão presentes em outros trechos como é a fala de R. no diálogo transcrito abaixo:

T: Eu acho que ele tem um certo medo da mudança.. de assumir as emoções dele e tal.

P: Será que ele entra em contato com o que ele sente? $N$ : Ele meio que cria uma barreira, pra se mostrar 'o fodão'.

P: Pra que será que ele cria isso?

R: Pra ser respeitado.

T: Acontece isso tanto no filme, quanto aqui né? (Trecho da transcrição do primeiro encontro, discussões a partir do documentário Pro dia nascer feliz, especificamente neste trecho os alunos dialogam sobre a personagem Douglas do Rio de Janeiro.)

Ao descreverem as necessidades da personagem, os alunos descrevem as próprias necessidades, o que os alunos acessam é apenas uma parte da realidade e acabam se identificando com alguns aspectos ressaltados no documentário. Desse modo, quando afirmam que o que a personagem realmente deseja é ser respeitado, ser valorizado, estão descrevendo os próprios desejos, de uma realidade individual que conhecem: a própria realidade que possui aspectos de identificação com os da personagem em questão.

Observe algumas das respostas dos jovens no $8^{\circ}$ encontro quando, mediados pelo documentário $\mathrm{O}$ Sal da Terra, deveriam responder qual sentido gostariam de atribuir à futura profissão.

R: Deixar uma marca por onde eu passar, de preferência boa, ajudar as pessoas, poder fazer o que estiver ao meu alcance.

M: Eu sempre gostei de que as pessoas depositassem confiança em mim, e me sentia totalmente útil. [...]. Enfim, pode parecer clichê, mas a minha intenção como psicóloga é fazer as pessoas se sentirem bem, e ao mesmo tempo me sentir bem pela confiança a qual a pessoa vai depositar em mim. (Atividades do $8^{\circ}$ encontro de resposta à pergunta: Qual o sentido eu gostaria de dar à minha futura profissão depois de assistirem trechos do documentário O Sal da terra.)

Em sua maioria, as respostas dos alunos nessa atividade foram permeadas pela necessidade de ser valorizado pela escolha da profissão e por um trabalho socialmente relevante. Apesar dessa iminente necessidade, quando dialogamos com os professores ou pesquisas a respeito do jovem na atualidade, poucos são os achados que nos permitem chegar a essa necessidade de ser reconhecido tão presente nos diálogos e produções dos adolescentes no grupo de Orientação Profissional.

Em especial, a classe de $3^{\circ}$ ano que fazia parte da pesquisa e era nominada pelos professores como apática ou pouco interessada, mais uma vez foi durante uma das discussões no grupo que foi possível compreender o modo como o grupo nominava esse distanciamento:

T: Eu não concordo porque, por exemplo, na nossa sala quem lê é só a A., e tem muita gente que tem vontade de ler, e se o professor faz isso [de indicar a pessoa que vai ler] todos poderiam ler.

$R$ : Se o cara é tímido, ele é tímido, velho, você vai forçar ele a se expor?

V: Mas cara, isso é convivio social!

T: É! Isso acontece aqui na escola, tipo como só a A. faz as leituras na sala de aula, tem professor que acha que ela é melhor que a gente por causa disso! (Trecho da transcrição do $12^{\circ}$ encontros, diálogo a respeito do filme Entre os muros da escola.)

Nesse diálogo, a partir do filme Entre os Muros da escola, os alunos demonstram querer ter oportunidades 
de fala em sala de aula, pois não ser reconhecido pelos professores é o mesmo que ser considerado como pior que os demais. Ou seja, o reconhecimento, mesmo que para uma leitura em sala de aula, vêm acompanhado do status de sabedoria e inteligência, atribuições ainda bastante valorizadas no contexto escolar.

Entretanto, é o mesmo anonimato, que eles negam, que possibilita a expressão das necessidades desses jovens. Visto que é no grupo, fortalecido pela confiança construída consequente de um espaço de fala e escuta, que tem como um dos critérios básicos o sigilo em relação ao que é dialogado naquele espaço, que esses jovens passam a se expressar, expressar os medos, as angustias e os sofrimentos que permeiam as escolhas que estão aprendendo a realizar no decorrer de seu desenvolvimento. Observe o trecho do diário de campo a seguir:

Algo importante também desse encontro foi descobrir que os alunos criaram um grupo de bate papo em um aplicativo de celular, nomeado por eles como Adolescentes Anônimos, com todos que participavam ou que já haviam participado do grupo, o que justificava que todos tivessem trazido as fotos da infância, pois se organizaram ao longo da semana para lembrar que essa era a atividade do próximo encontro. (Trecho do diário de campo do $6^{\circ}$ encontro em que foram utilizadas as leituras de imagem de Escher e finalização da construção da linha do tempo.)

Passam a se denominar Adolescentes Anônimos todos os que participam do grupo a partir do momento em que entendem que aquele é um espaço para que eles possam se expressar de modo seguro, protegido.

Ao retomar, então, a ideia de Vigotski (1931/2006) sobre os movimentos dialéticos do desenvolvimento, podemos compreender que: o que pode estar na base do que é identificado como desinteresse pelos professores, é a própria necessidade dos jovens de serem reconhecidos enquanto sujeitos que se expressam, pensam e trabalham o mundo a sua volta. Ou seja, enquanto sujeitos protagonistas também do contexto que os constitui.

Não se trata, assim, de um sujeito passivo no processo de ensino e aprendizagem, e, consequentemente, de seu próprio processo de desenvolvimento. $\mathrm{O}$ que os dados apresentados até aqui evidenciam é que os adolescentes agem, permanentemente, frente às demandas da realidade, configurando significados e sentidos sobre o vivido que, por sua vez, passam a influenciar seu pensamento e decisões. Sujeitos que necessitam de um espaço para ressignificar as próprias vivências e apropriar-se de um modo de ser próprio, delineado por suas necessidades e desejos. Qual história de relações vem sendo configuradas nas vidas desses adolescentes destituídos do lugar de fala e de protagonismo nos próprios ambientes escolares?

Talvez não cheguemos às respostas para essas perguntas, o que podemos compreender é que a fala subordina a ação e é a função volitiva da palavra que sustenta a função planejadora e organizadora da ação (Vigotski, 1931/2006), portanto a possibilidade de regulação da própria conduta só se torna possível a partir de um coletivo que possibilite a formação de sujeitos protagonistas de suas próprias trajetórias.

Ou seja, os múltiplos cenários que configuram as situações sociais de desenvolvimento capazes de produzir vivências que ressignifiquem a relação do jovem com o momento de escolha profissional não se constituem enquanto coletivos capazes de sustentar a possibilidade de regulação da própria conduta desses jovens. E sim, enquanto cenários que sustentam o sofrimento desses jovens destituídos de seus papéis de protagonistas de suas respectivas vidas.

\section{Considerações finais}

Podemos perceber, portanto, que o que era identificado, no início da pesquisa, como desinteresse pelos professores se manifestava, dialeticamente, no grupo de Orientação enquanto necessidade de protagonismo dos adolescentes, pois em um processo de ensino e aprendizagem que carece de um sujeito ativo a fim de que garanta o próprio processo de desenvolvimento, o aluno percebe que o único ativo da relação é o professor.

A perversidade está em esperar e exigir que o jovem tenha domínio da própria conduta, a fim de que tenha condições de realizar escolhas, daqueles que são frequentemente destituídos do lugar do discurso e protagonismo dentro dos múltiplos cenários que constituem e são constituídos. Somente a partir de um coletivo, que se configura como situação social de desenvolvimento favorecedora de vivências promotoras de significação é que será possível constituir o protagonismo como modo de ser e agir dos jovens. Isso os tornará capazes de compreender as implicações de suas escolhas, como também assumir-se como sujeito de sua história e trajetória.

Sem espaços para a reflexão a respeito de todas essas expectativas que se veem obrigados a cumprir, como o estabelecimento de metas de sucesso inatingíveis em um mercado de trabalho neoliberal que nem ao menos adentraram, os jovens se refugiam no silêncio enquanto única possibilidade de protagonismo dentre os cenários que os constitui. 
É esse mesmo silêncio que nos propicia o acesso às emoções que fundamentam a autorregulação e, consequentemente, a atitude de escolher. $\mathrm{O}$ que buscamos é que as emoções possam ser acessadas, na medida em que são elaboradas e nomeadas a partir de uma reflexão crítica do jovem, muitas vezes expressa pelo silêncio.

Cabe questionar se nós, psicólogos, que ocupamos, muitas vezes, o lugar de orientadores profissionais nas escolas, estamos preparados para lidar com os silêncios e tensões e mesmo o sofrimento desses jovens que chegam até nós na ânsia de que os livremos da angústia da dúvida. $\mathrm{O}$ que estamos fazendo com as possibilidades de escolha que o sujeito possui quando lhes damos respostas prontas sobre um futuro que não cabe a nós, enquanto profissionais, predizer ou imaginar?

Não há modelos de práticas a serem seguidos, mas é importante ressaltar que a prática de Orientação Profissional que sustenta esta pesquisa, nos possibilita colocar o sujeito no lugar de protagonista de sua história a fim de que possa ampliar consciência, significar e conviver com suas inseguranças e incertezas e, só assim, poder se perceber livre para escolher para além das amarras das expectativas de outros que não ele próprio. Trata-se de uma prática promotora de tomada de consciência, promotora de desenvolvimento. É esse o principal papel que o psicólogo deve exercer em contextos educativos - criar condições materiais e simbólicas de promoção de desenvolvimento. Uma prática que, ao ultrapassar os diagnósticos e testes tão frequentemente atribuídos ao psicólogo escolar, passa a proporcionar o protagonismo de sujeitos desprovidos deste papel nos múltiplos cenários que os configuram.

Portanto, o que obtivemos com este trabalho vai além do que é denominado como Orientação Profissional. Atende aos caminhos de uma prática de psicologia escolar, que apesar da vasta produção de pesquisas em perspectivas críticas, ainda carece de estudos como os que estão sendo desenvolvidos pelo PROSPED a fim de que possamos, como profissionais psicólogos, configurar relações capazes de se constituir enquanto situações sociais promotoras de desenvolvimento humano.

\section{Referências}

Aguiar, W. M. J. (2006). A escolha na orientação profissional: contribuições da psicologia sócio-histórica. Psicologia da Educação, (23), 11-25. Recuperado em 23 de junho de 2016, de http://pepsic.bvsalud.org/pdf/psie/n23/ v23a02.pdf

Aguiar, W. M. J., Bock, A. M. M., \& Ozella, S. A. (2007). Orientação profissional com adolescentes: um exemplo de prática na abordagem sócio-histórica. In A. M. B. Bock, M. G. M. Gonçalves, \& O. Furtado (Orgs.), Psicologia sócio-histórica: uma perspectiva crítica em psicologia (3a. ed., pp. 163-178). São Paulo: Cortez.

Aguiar, W. M. J., \& Ozella, S. (2006). Núcleos de significação como instrumento para a apreensão da constituição dos sentidos. Psicologia: ciência e profissão, 26(2), 222-245. Recuperado em 15 de maio de 2016, de http://pepsic. bvsalud.org/pdf/pcp/v26n2/v26n2a06.pdf

Alvim, J. L. (2011). O papel da escola na orientação profissional: uma análise contemporânea da dimensão teórica e prática na cidade de Presidente Prudente-SP. Dissertação de mestrado, Universidade Estadual Paulista "Júlio de Mesquista Filho" - UNESP. Presidente Prudente.

Alvim, J. L., \& Menin, M. (2012). A Escola contemporânea: orientação para a profissão ou para a competição? In Psicologia.pt: o portal dos psicólogos. Recuperado em 15 de maio de 2016, de http://www.psicologia.pt/artigos/ textos/A0603.pdf

Bock, A. M. B., \& Aguiar, W. M. J. (1995). Por uma prática promotora de saúde em orientação vocacional. In A. M. B. Bock, C. M. M. Amaral, \& F. F. Silva. A escolha profissional em questão (2 ed.) (pp. 9-23). São Paulo: Casa do Psicólogo.

Bock, S. D. (2002). Orientação Profissional: A abordagem sócio histórica. São Paulo: Cortez.

Clot, Y. (2014). Vigotski: a consciência como relação. Psicologia \& Sociedade, 26(2), 124-139. Recuperado em 13 de agosto de 2015, de http://www.scielo.br/pdf/psoc/v26nspe2/a13v26nspe2.pdf

Conde, D. L. G. (2012). Escolha profissional na contemporaneidade: caminhos possíveis. Tese de Doutorado, Universidade Federal do Rio de Janeiro, Rio de Janeiro.

D“Avila, G. T., \& Soares, D. H. P. (2003). Vestibular: fatores geradores de ansiedade na "cena da prova”. Revista Brasileira de Orientação Profissional, 4(1-2), 105-116. Recuperado em 03 de setembro de 2016, de http://pepsic.bvsalud.org/ $\mathrm{pdf} / \mathrm{rbop} / \mathrm{v} 4 \mathrm{n} 1-2 / \mathrm{v} 4 \mathrm{n} 1-2 \mathrm{a} 10 . \mathrm{pdf}$

Oliveira, A. dos S. (2009). Os sentidos da escolha da profissão, por jovens de baixa renda: um estudo em psicologia sócio-histórica. Tese de Mestrado, Pontifícia Universidade Católica, São Paulo, SP, Brasil. 
Petroni, A. P., \& Souza, V. L. T. (2014). Psicólogo escolar e equipe gestora: tensões e contradições de uma parceria. Psicologia: Ciência e Profissão, 34, 444-459. DOI: http://dx.doi.org/10.1590/1982-3703000372013

Petroni, A. P. (2013). Psicologia escolar e arte: possibilidades e limites da atuação do psicólogo na promoção da ampliação da consciência de gestores. Tese de Doutorado, Pontifícia Universidade Católica, Campinas.

Pino, A. (2000). O social e o cultural na obra de Lev. S. Vigostki. Educação e Sociedade, 71, 45-78. DOI: https://dx.doi. org/10.1590/S0101-73302000000200003

Souza, V. L. T., Petroni, A. P., \& Dugnani, L. A. C. (2011). A arte como mediação nas pesquisas e intervenção em Psicologia Escolar. Em R. S. L. Guzzo, \& C. M. Marinho-Araujo. Psicologia Escolar: identificando e superando barreiras. (pp.261-285). Campinas, SP: Alínea.

Veresov, N. (2012). Perezhivanie and cultural development: a key which opens the door? Working paper presented to the International Research Group for Early Childhood Education and Development, Monash University, Melbourne. (Mimeo.)

Vigotski, L. S. (1931/1995). Dominio de la propria conducta. In: Vygotsky, L. S. Obras Escogidas: Historia del desarrollo de las funciones psíquicas superiores, III, 285-302, 2. ed. Madrid: Visor.

Vigotski, L. S. (1931/2006). Obras escogidas. Tomo III. Trad. Lydia Kuper. Madrid: Visor.

Vigotski, L. S. (1935/2010). Quarta aula: a questão do meio na pedologia. Tradução: Márcia Pileggi Vinha. Psicologia USP, São Paulo, 21(4), p. 681-701.

Vigotski, L. S. (1932/2001). A construção do pensamento e Linguagem. São Paulo, Martins Fontes.

Vigotski, L. S. (2001). Psicologia da Arte. São Paulo: Martins Fontes. (Original publicado em 1925).

Whitaker, D. C. A. (2010). Da "invenção" do vestibular aos cursinhos populares: um desafio para a Orientação Profissional. Revista Brasileira de Orientação Profissional, 11(2), 289-297. Recuperado em 12 de abril de 2016 em http://pepsic. bvsalud.org/pdf/rbop/v11n2/v11n2a13.pdf

Recebido: $17 / 03 / 2017$

$1^{a}$ revisão: $18 / 10 / 2017$

$2^{a}$ revisão: 09/12/2017

Aceite final: $15 / 01 / 2018$

Sobre os autores

Fernanda Pereira Medeiros é psicóloga graduada pela Universidade Estadual Paulista Júlio de Mesquita Filho - UNESP. Mestre e doutoranda em Psicologia pela Pontifícia Universidade Católica de Campinas/SP.

Vera Lúcia Trevisan de Souza é docente e pesquisadora do Programa de Pós-graduação em Psicologia da Pontifícia Universidade Católica de Campinas. 